\title{
Organizações Outras: Diálogos Entre a Teoria da Prática e a Abordagem Decolonial de Dussel
}

\section{Organizations Others: Practice Theory and Dussel's Decolonial Approach Dialogues}

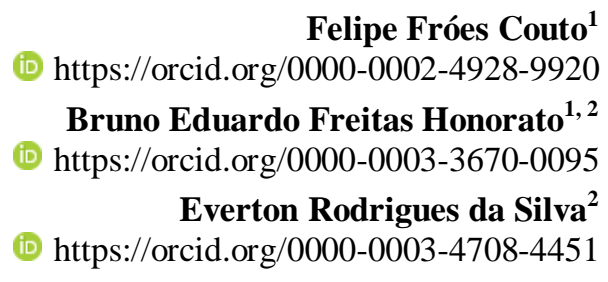

Universidade Federal de Minas Gerais, Faculdade de Ciências Econômicas, Belo Horizonte, MG, Brasil ${ }^{1}$

Universidade Federal de Alfenas, Instituto de Ciências Sociais Aplicadas, Varginha, MG, Brasil ${ }^{2}$ 


\title{
Resumo
}

O objetivo deste ensaio é propor um alinhamento teórico possível entre o aporte dos estudos decoloniais latinoamericanos - com ênfase no trabalho de Enrique Dussel - e a abordagem teórico-metodológica da teoria da prática, partindo de um entendimento específico do debate centro/periferia para adentrar a forma de capturar as organizações em sua localidade. $\mathrm{O}$ argumento central defendido aqui é que, partindo-se do pressuposto de que as organizações não acompanham modelos genéricos, neutros e supostamente universais, elas podem e devem ser capturadas dentro da localidade em que se realizam. Nesse sentido, propõe-se a abordagem decolonial como aporte teórico para aproximação das organizações em seu contexto e a teoria da prática como forma de conhecê-las em seu movimento cotidiano, habitual, corriqueiro e, por vezes, improvisado.

Palavras-chave: estudos organizacionais; decolonialismo; organizing; organizações alternativas; prática organizacional.

\begin{abstract}
The aim of this essay is to propose a possible theoretical alignment between the contribution of Latin American decolonial studies - with emphasis on the work of Enrique Dussel - and the theoretical-methodological approach of the theory of practice, starting from a specific understanding of the center / periphery debate for capturing the organizations in their locality. The central argument advocated here is that, assuming that organizations do not follow generic, neutral, and supposedly universal models, they can and should be captured within the locality in which they take place. In this sense, it is proposed the decolonial approach as a theoretical contribution to the approximation of the organizations in their context and the theory of practice as a way of knowing them in their daily, habitual, commonplace and sometimes improvised movement.
\end{abstract}

Keywords: organization studies; decolonialism; organizing; alternative organizations; organizational practice.

JEL Code: D21, D23, F54. 


\section{Introdução}

O objetivo deste ensaio é propor um alinhamento teórico possível entre o aporte dos estudos decoloniais latino-americanos - com ênfase no trabalho de Enrique Dussel - e a abordagem teórico metodológica da teoria da prática, partindo de um entendimento específico do debate centro/periferia, abrindo espaço para a compreensão das organizações como um fenômeno localizado.

Adota-se: (a) a abordagem decolonial como proposta para pensarmos as organizações em termos de um contexto, práticas, cultura e significados específicos; e (b) a teoria da prática como uma possibilidade para capturar essas singularidades do gerir e de conhecer o modo específico de gerir praticado por organizações que não se enquadram no modelo naturalizado da gestão. $\mathrm{O}$ argumento central defendido aqui é que, partindo-se do pressuposto de que as organizações não acompanham modelos genéricos, neutros e supostamente universais, elas podem e devem ser capturadas na localidade em que se realizam.

Nesse sentido, propõe-se a abordagem decolonial como aporte teórico para aproximação das organizações em sua localidade e a teoria da prática como forma de conhecê-las em seu movimento cotidiano, habitual, corriqueiro e, muitas vezes, improvisado. O uso do termo capturar, nesse trabalho, não é fortuito. Entende-se que tais singularidades do gerir e os modos de ser das organizações apenas podem ser capturadas, no sentido de serem percebidas, entendidas e registradas pelo pesquisador no momento da pesquisa. A noção de capturar sugere a incorporação de práticas e conexões mobilizadas no fazer organizacional no registro da ciência. Momento sui generis do contato do pesquisador com a realidade pesquisada em seu devir constitutivo.

As teorias administrativas do século XX fizeram e ainda têm feito um duplo movimento de construção da realidade organizacional (de como as organizações devem ser) e de ornamentação dessa realidade sob o manto de uma racionalidade científica (Carrieri, 2012). Tal processo ocorre por meio da construção de conhecimentos gerenciais tidos como puros ou neutros (porque provenientes da razão científica), absolutos e universais (porque excluem saberes locais/tradicionais) que triunfaram política e economicamente por meio das tecnologias de gestão de base euro-americanas ( Alcadipani \& Caldas, 2012; Alcadipani, Khan, Gantman, \& Nkomo, 2012; Carrieri, 2012; Frenkel \& Shenhav, 2006).

Como afirmam Alvesson e Deetz (1996), Davel e Alcadipani (2003), Ibarra-Colado (2006) e Alcadipani (2011), há uma naturalização dos processos administrativos, da gestão, dos fenômenos organizacionais, nas teorias administrativas consideradas hegemônicas. Para esses autores, tal movimento de naturalização minimiza (ou retira) o papel do contexto sociohistórico na construção do conhecimento, propagando a existência de modelos universais de gestão.

Autores como Willmott (1997), Collinson (2006), Heracleous (2006) e Alvesson, Hardy e Harley (2008) questionaram a produção de verdades totalizantes sobre a gestão e sobre os modelos explicativos da realidade nas organizações. Proclamam os autores que cabe aos estudiosos da Administração desvelar o cotidiano organizacional a partir de suas outras verdades, discursos e narrativas - não a grande verdade em si. Para Ibarra-Colado (2006), é preciso fomentar o pluralismo e os diferentes debates, inibindo o discurso monolítico e universal. A realidade da gestão é múltipla, diversa, e pode ser observada, estudada no cotidiano das pessoas, nas estratégias e práticas de sobrevivência na organização que se produz diariamente a partir de seus condicionantes culturais.

Nesse sentido, entendemos que enxergar as organizações a partir de suas categorias tradicionais de análise - hierarquia, porte, eficiência/eficácia econômica, áreas funcionais, dentre outras, centradas num paradigma científico moderno que privilegia o entendimento da realidade como um estado de ordem e estabilidade, significa manter-se preso a uma janela mental (uma janela mental transparente, citando Cooper, 1990) que reproduz o conhecimento naturalizado (euro-americano) da gestão. Tais discursos de garantia de ordem moldaram a história das ideias na Administração (Cooper, 1990; Reed, 2010; Tsoukas \& Chia, 2002), de tal forma que se supõe que essa seria a única lógica possível para se pensar a gestão (Reed, 2010; Zilio, Barcellos, Dellagnelo, \& Assmann, 2012). 
Acreditamos que visões alternativas das organizações (Miettinen, Samra-Fredericks, \& Yanow, 2010; Schatzki, 2006), isto é, das organizações como uma multiplicidade de processos (multiníveis) no aqui e agora, ligados a uma história - lógica que sugere fluidez, estados de alternância entre estabilidade-instabilidade e desconstrução-construção cotidiana, são mais adequadas para entender os modos de organizar (as práticas organizativas), sem que essa perspectiva implique, de modo algum, a busca por um organizar universal. Por essa razão, afirmamos que a organização, entendida por meio de categorias analíticas reificadas, é apenas um input para a ação humana; ao passo que, uma vez compreendida sob a forma de padrões emergentes, significa o resultado da ação humana em tramas específicas.

Nesse sentido, propomos, neste trabalho, um alinhamento de duas possibilidades teóricas para capturar as singularidades do gerir, em especial para conhecer o modo específico de gerir praticado por organizações que não se enquadram no modelo naturalizado da gestão. Cabe pontuar, seguindo Cavalcanti e Alcadipani (2013, p. 562), que pensar dessa forma "não pressupõe um possível "enfraquecimento"" ou distanciamento do objeto de estudo da Administração, mas significa caminhar em direção contrária, optando por buscar subsídios conceituais que permitem compreender a natureza mutante da realidade social. Tal enquadramento político-epistêmico nos leva a compreender o site (palavra empregada por Schatzki, 2005) de acontecimento das organizações, ou seja, conduz-nos às dimensões que configuram o cotidiano em sua localidade.

Assim, buscamos, na seção dois, falar sobre os fundamentos teóricos para se estudar as organizações a partir da abordagem decolonial de Dussel (2005), entendendo a possibilidade de existência de organizações outras, isto é: (a) exteriores à totalidade que mantem o sistema colonial centro-periferia; (b) cuja práxis subverte e transpassa a ordem fenomenológica de uma organização como continuidade funcional da sociedade ocidental; e (c) cujos preceitos de atuação estejam radicados na noção de proximidade compreendida pelo autor como verdadeira libertação da alienação ao ser ontológico da totalidade.

$\mathrm{Na}$ seção três, apresentar os fundamentos teóricos para o estudo das organizações como elas acontecem, entendendo: (a) a gestão feita pelo homem comum; (b) que se (re)constrói no dia a dia (c) a partir de um saber comum, histórico; (d) no seu espaço habitual, corriqueiro; (e) em que se estabelece práticas regulares, frequentes, bem como improvisações contínuas. Pretendemos, pois, direcionar a atenção para os saberes práticos (Barros, Cruz, Xavier, \& Carrieri, 2011) que também constituem o que chamamos de gestão.

Por fim, propomos, na seção de discussão, um alinhamento entre tais teorias como possibilidade oportuna para pesquisar organizações à luz dos pressupostos discutidos no artigo e encerraremos com recomendações para uma agenda de pesquisa em torno do tema.

\section{A Administração Totalizada e a Perspectiva Decolonial das Organizações}

Ao longo deste ensaio, posicionaremos nosso pensamento contrapondo-o à visão quasi-natural de que as organizações hegemonicamente demandam estruturas, hierarquia e formatos organizativos. Entendemos que as teorias contemporâneas da Administração têm se concentrado em uma única receita nas formas da empresa e de organizações econômico-racionais, cada vez mais uniformes e incapazes de promover a emancipação do ser humano.

Para tal, importante entender que esta visão naturalizada da Administração não nos foi trazida de maneira espontânea, mas construída historicamente pelos interesses políticos das potências centrais que chamaram para si a legitimidade teórica do campo nas figuras de Taylor, de Fayol e de vários outros autores americanos - cujo interesse material era a expansão do sistema capitalista e da condição de dependência nos países periféricos durante o contexto da guerra fria (Barros, 2014; Barros \& Carrieri, 2015). 
Esse movimento teórico totalizante - histórica e estrategicamente arquitetado - pode ser melhor compreendido quando lançamos um olhar crítico sobre a história e sobre o mito da modernidade (Escobar, 1988; Ibarra-Colado, 2012), que lançou ao método científico e à produção de documentos o status de fonte de conhecimento genuíno e validado (Abdalla \& Faria, 2017; Chakrabarty, 2011).

Os estudos organizacionais, segundo Ibarra-Colado (2006), foram objeto de colonialidade epistêmica nos últimos 160 anos. Cronologicamente, para o autor, os saberes em Administração foram construídos primeiramente pelos conhecimentos de engenharia, seguidos pelos conhecimentos de psicologia e, por fim, nos conhecimentos de gestão. O tratamento dado a esses saberes científicos era provido de uma necessária utilidade para resultados produtivos (lucrativos) de organizações capitalistas (empresa), o que influenciou fortemente o desenvolvimento funcional dos saberes e das racionalidades instrumentais que permearam as teorias da Administração (Abdalla \& Faria, 2017; Ibarra-Colado, 2006).

Sob o mote do discurso administrativo-racional, constituiu-se a ideia de que os saberes científicos da Administração seriam capazes de prover o progresso e o desenvolvimento de organizações em quaisquer contextos (Escobar, 1988; Ibarra-Colado, 2012). Isso foi muito importante no contexto de pós-guerra (1945-adiante), em que os países ditos modernos (principalmente na Europa e os Estados Unidos da América) precisavam escoar uma produção excedente que não era absorvida pelos países do Sul (África, América Latina e o Oriente). Esses países, munidos de um discurso moderno, buscaram impor a esses países não-modernos um modelo de consumo pela noção de subdesenvolvimento - em que as pessoas deveriam consumir bens produzidos em outros países para ter uma melhor qualidade de vida. A ausência de conhecimentos tecnológicos e científicos que desenvolvessem a economia nos moldes dos países centrais se tornou problema global (Ballestrin, 2013; Escobar, 1988).

O discurso do subdesenvolvimento deu origem a dois movimentos estratégicos: (a) de um lado, à profissionalização do desenvolvimento; de outro, (b) à institucionalização do desenvolvimento. $\mathrm{O}$ primeiro diz respeito à adoção da ciência moderna da Administração como parâmetro do conhecimento verdadeiro que deveria ser ensinado aos filhos das elites locais que, doravante, seriam reconhecidos em seus países como profissionais especializados em desenvolvimento (jurídico, econômico, social, político, etc.), o que deu origem a um movimento migratório de estudantes destes países para as Universidades europeias e norte-americanas. No caso do Brasil, notoriamente para Universidades Portuguesas; no campo da administração, o conhecimento fora efetivamente afirmado a partir de elites do Sudeste que foram estudar em Universidades Norte-Americanas (Barros \& Carrieri, 2013). Já o segundo é o estabelecimento de um campo de conhecimento hegemônico nos países do sul compostos por teorias do Norte e realidades do Sul - que iniciou um processo de desenvolvimento científico de documentos, livros e registros de uma ciência que ditariam as verdades nos países do Sul conforme um olhar institucionalizado do Norte (Escobar, 1988; Prasad, 2016).

Logo, a produção de conhecimentos, livros e teorias em países subalternos (africanos, latinoamericanos e de culturas orientais em geral) ainda não se mostra madura o suficiente para abranger, com olhares de povos genuinamente sulistas, sobre as questões das origens dos hábitos e costumes locais; sobre o desenvolvimento das práticas e das culturas locais e nem sobre o estado presente e futuro dos estudos organizacionais nos países que não estão inseridos no eixo ocidental (Chakrabarty, 2011).

Para alguns autores, por exemplo, a produção latino-americana sobre práticas saberes locais de gestão não são do interesse de países do Norte, e conhecimento aqui produzido fica relegado à uma condição subalterna ou periférica (Carvalho, Ipiranga, \& Faria, 2017). Tal fato decorre, entre outros fatores, de: (a) falta de capacidade comunicativa e organizacional entre os países da América Latina para fortalecer uma comunidade do Sul; (b) inexistência de revistas e comunidades acadêmicas que contraponham os gatekeepers do Norte; (c) associações científicas recentes e pequenas (Bertero, Alcadipani, Cabral, Faria, \& Rossoni, 2013; Rodrigues, Duarte, \& Carrieri, 2012) e, adicionalmente a tais restrições, (d) porque pesquisadores de importantes instituições nacionais de pesquisa e desenvolvimento em Administração direcionam seus esforços ao centro com teorias anglo-saxônicas que são entregues "com um sotaque latino e com um perfume tropical" (Ibarra-Colado, 2006, p. 465). 
O esforço da produção de conhecimentos universais pertence ao mito da modernidade (Escobar, 1988), logo, integra o projeto totalizante de uma ciência desenvolvimentista ocidental. É importante, então, problematizar quais são os saberes produzidos para representar a realidade latino-americana, e quais são os saberes que claramente reproduzem modelos teóricos universalistas que visam elevar o status internacional de pesquisadores que continuam reproduzindo práticas seculares de dominação ideológica dos países ocidentais. Perguntamos provocativamente ao leitor: onde estão os esforços para se pensar teorias e conhecimentos que partem da realidade local e se direcionam a esta mesma realidade local?

Partindo deste pressuposto, é importante compreender que parte substantiva dos saberes produzidos sobre organizações brasileiras devem ser provincializados a partir do seu lugar subjetivo de produção (Carvalho et al., 2017; Chakrabarty, 2011). Não é mais suficiente pensar em uma teoria geral ou uma forma genérica de analisar as organizações, mas compreendê-las dentro de um contexto de práticas, de culturas e de significados que são típicos da localidade onde o fenômeno ocorre. Um pensamento decolonial, nesse sentido, será a rejeição da totalidade proposta pelo pensamento ocidental sobre as organizações para compreender perspectivas mais amplas da ação de organizar.

\section{A totalidade e o "pensar as organizações a partir do outro"}

A noção da totalidade é essencial para a compreensão do pensamento decolonial e é uma categoria central da obra de Enrique Dussel (1977). Para explicá-la didática e imageticamente, iremos recorrer metaforicamente a alguns construtos de Bourdieu (1989). Ainda que esta transposição de autores seja considerada uma transgressão do pensamento original de Dussel, acreditamos que é importante ter um entendimento integrado desses construtos, principalmente em razão da leitura de Bourdieu ser útil para o entendimento de conceitos mais amplos e vastos, como os propostos por Dussel. Para Bourdieu, o poder está em tudo, e é preciso saber enxergá-lo onde ele é invisível ou ignorado especialmente nos símbolos que nos cercam e nas estruturas de criação de significado nas quais somos socializados. A objetividade do sentido do mundo define-se pela concordância dos seres racionais sobre qual deve ser o significado de um objeto (Bourdieu, 1989). O símbolo é o resultado de uma práxis negociada que integra socialmente os sujeitos - dessa forma, a linguagem, por exemplo, é uma estrutura criada para estruturar a ordem gnoseológica, ou criar sentidos imediatos -, de modo que os significados e sentidos são produzidos e apropriados por sujeitos legitimados que produzem e negociam significados entre si (Bourdieu, 1989).

Ora, a coexistência de uma sociedade é o resultado de uma práxis que, quando reproduzida e institucionalizada historicamente, se constitui num hábito (habitus), que dará origem a tradições. Essas tradições, segundo Bourdieu (1989) se estruturam constituindo campos de várias ordens: campos políticos, campos econômicos, campos científicos, campos sociais, etc. Um campo só pode ser explicado a partir da análise do seu surgimento histórico, da sua sedimentação e das regras que regem as interações entre os agentes que compõem o campo, que possui suas próprias dinâmicas (Bourdieu, 1989).

Cada campo é composto por agentes distintos, que possuem interesses que se contrapõem e constituem disputas internas, que podem dar origem a dois desdobramentos possíveis: ou a ressignificação do campo (conforme o interesse dos agentes que detém maior poder), ou a ruptura do campo para a constituição de um novo campo, que passa a se contrapor ao campo anterior (Bourdieu, 1989). Em ambos os casos, para Bourdieu, as disputas políticas constituirão conflitos que levarão, necessariamente, a rupturas de agentes que buscarão legitimar suas próprias pretensões- o que dá origem a uma luta pela legitimidade.

Agora convidamos o leitor a imaginar, metaforicamente, que essa luta pela legitimidade fosse respondida com violência pelos sujeitos que detêm maior poder dentro de um campo. Que os mais poderosos, diante da divergência dos menos poderosos, empregassem o uso do argumento de que aqueles que discordam do sistema de sentidos existentes em um campo não são sujeitos capazes de possuir legitimidade, e que questionassem o status de humanidade desses sujeitos. Que os dissidentes sejam submetidos, então, à negação do seu status de sujeito. Neste cenário metafórico, a dissidência e a 
luta política são impraticáveis pelos atos de tirania dos detentores de poder dentro de um campo, que constituem, no seu sistema de significados, a única saída possível, e atribuem aos seus símbolos e ao seu campo o status de ontológico (realidade).

Está articulada, então, a ideia de totalidade de Dussel (1977). Na totalidade, os agentes constituem um ego cogito (a ideia de serem os verdadeiros sujeitos detentores da razão e do conhecimento superior), notoriamente existente no caso do homem europeu iluminista dos Séculos XV a XVIII, que resultará na negação do status de humanidade de outros povos que não seguissem a matriz europeia. Por essa razão, a história passa a tratar o homem europeu como civilizado e os outros povos como incivilizados: bárbaros, indígenas, asiáticos, etc., como povos selvagens e incapazes da razão como preconizada pelo olhar ocidental - agora moderno. O ego cogito deriva, segundo o autor, de um ego conquiro, ou seja, a crença de que é um dever divino do homem europeu levar a sua tecnologia e os seus modos de vida às demais populações do mundo, rejeitando as suas crenças, religiões e culturas em prol de um projeto global de padronização da vida econômica e política europeia (Dussel, 1977).

A esse campo único, que rejeitou historicamente os demais campos por meio da violência, do genocídio e da escravidão, Dussel vai nominar totalidade, que agora passa a ser vista como a única forma de existência possível, ou forma ontológica de existência do homem. Àqueles que mantém a sua resistência é atribuída a condição de exterioridade, ou seja, de negação da inserção no campo pela recusa ou pela não-inserção ao sistema de normas (ex.: indígenas, sertanejos e demais populações vulneráveis submetidas à pobreza na América Latina, na África ou em países asiáticos). O conceito de exclusão e pobreza, que para muitas sociedades não existia antes da conquista pelos povos europeus, passou a ser a realidade de todos aqueles relegados à exterioridade.

Dussel (2005) quando versa sobre a totalidade, ou ontologia, que é a ideologia das ideologias e que mantem o sistema colonial centro-periferia, aponta que a totalidade, o sistema, tende a totalizar-se, a autocentrar-se, e a pretender, temporalmente, eternizar sua estrutura presente; espacialmente, a incluir intra-sistematicamente toda exterioridade possível. A noção de totalidade ocidental inclui a noção de dominância. Os heróis ocidentais dominadores que manifestaram na terra os deuses - em outras épocas - agora empreendem a democracia, a liberdade e a civilização como normas. A expansão dialéticodominadora do Mesmo, que assassina o Outro e o totaliza no Mesmo. Tal noção aponta a diferença como representação do não-ser, do caos e do mal (Couto \& Carrieri, 2018; Misoczky \& Camara, 2015).

Desse modo, em nome da civilização, das boas práticas e de uma suposta modernização, a totalidade ocidental tem abarcado a diferença como ameaçadora e devorado as suas possibilidades de crescimento em todos os âmbitos. A passagem da ontologia, ou da totalidade, ao transontológico, isto é, a passagem do que está ao alcance do ser, para àquilo que está além do ser, isto é, o Outro é o que buscamos a partir da noção de exterioridade de Dussel.

Para Dussel (2005), o Outro é exterioridade de toda totalidade porque é livre. Não está incluso. Não pode ser compreendido pela ontologia e, portanto, é transontológico. A noção de organizações Outras remete ao sentido dado por Dussel ao termo Outro, i.e. a externalidade da totalidade. Especialmente, tomando a exterioridade como categoria possível para uma analítica dos modos de existência organizacionais. Se a noção de totalidade de Dussel (2005) acarreta a insaciável incorporação dos modos de ser alternativos que aparece quando desaparecem as relações face-a-face, é a noção de proximidade é o que vem revitalizar as relações humanas e evitar que sejamos todos devorados por um único modo de existência: o Ocidental (Couto \& Carrieri, 2018).

Pensar além da exterioridade quer dizer considerar o Outro como ponto de partida, ou seja, a organização não-hegemônica ou as práticas locais como formas poiéticas de organização social - para além da empresa e dos formatos organizativos que conhecemos. Dussel $(1977,2005)$ propõe a superação de uma forma organizativa totalizante que considere os seres humanos como objetos dentro de um sistema (proxemia) para compreender possibilidades em que um sujeito reconheça o Outro também como sujeito existente no meio natural e com quem compartilhamos experiências genuinamente humanas (proximidade). Enquanto na proxemia tratamos objetivamente as relações sociais por meio de seu caráter artificialmente utilitário (comprar, contratar, negociar), na proximidade estamos falando de 
experiências que nos levam ao contato subjetivo-sensorial mais próximo do que sustenta nossa alteridade pelo próximo (abraçar, compartilhar, beijar, etc.) (Couto \& Carrieri, 2018; Dussel, 1977).

A proximidade para Dussel (2005) é uma noção de aproximar-se com respeito e tentar compreender, no sentido de abrir-se a possibilidade do outro, ouvir e arriscar-se a percebê-lo como amigo. Para o autor, só quem viveu a proximidade na justiça e na alegria assume a responsabilidade pelo outro a quem deseja na proximidade dos iguais. Tanto a primeira proximidade, que retoma o nascer da criança no ventre da mãe, como a última proximidade, entre irmão e amigos, são sempre festa. A festa, que para Dussel (2005), indica uma categoria metafísica da proximidade realizada, como alegria. Ao passo que, por alegria se entende a realização do real e a satisfação da coincidência do desejo e do desejado. Estar em festa e na proximidade da amizade é o que promove a abertura para compreensão, a confiança e responsabilidade pelo que não é o Mesmo. Só essa compreensão é fonte de libertação da alienação, no sentido de Dussel (1977), provocada pela imersão na totalidade do Sistema Mundial.

Ainda conforme Dussel (2005), um movimento analético é necessário para o desenvolvimento de uma epistemologia decolonial: não basta apenas registrar e analisar a experiência do Outro, mas é importante também estar junto ao Outro, compreendendo as suas peculiaridades e denunciando as formas de constrição que o diferente sofre ao ser contraposto à totalidade (Couto \& Carrieri, 2018; Dussel, 1977; Misoczky \& Camara, 2015).

A análise das práticas locais, bem como a valorização dos saberes locais e o esforço analético (denúncia e resistência) são as premissas pelas quais os pesquisadores assumirão a responsabilidade de contribuir para a libertação das formas hegemônicas existentes no mainstream. Ao abordarmos os Estudos Organizacionais, é importante colocar com clareza a possibilidade de investigação de formas de organizar a vida e de sobrevivência alternativas àquelas dos discursos monolíticos e universais presentes nas visões totalizantes da Administração. Partindo do pensamento de Enrique Dussel e dos níveis de reflexão que ele desenvolve em sua Filosofia da Libertação, podemos pensar organizações cuja práxis subverte e transpassa a ordem fenomenológica da organização como afirmação de uma totalidade funcional e continuidade ontológica do ocidente.

Como se organizam as comunidades que se fundamentam pelas relações de proximidade dos sujeitos entre si e com a natureza (compadrio, reciprocidade, simbiose com o meio ambiente)? De que forma podemos pensar organizações alternativas a partir de saberes locais que, anteriormente, não foram registrados ou validados cientificamente pela história? De que forma podemos pensar e compreender as relações de trabalho dentro das organizações em uma perspectiva dos costumes, hábitos e práxis locais? Em quê nos diferenciamos da totalidade ocidental imposta? São perguntas que ainda precisam ser melhor respondidas pelos pesquisadores que assumem a responsabilidade de se pensar uma teoria genuinamente sulista e preocupada com o desenvolvimento dos locais de onde se origina.

Nesse sentido, no próximo tópico propomos a teoria da prática como uma possibilidade para pensarmos a pesquisa das organizações como elas acontecem ou das organizações em seu cotidiano. Nós acreditamos que é possível fazer uso da teoria desenvolvida a partir da incursão teórica de Weick (1979) - e daqueles que partem de uma crítica à organização como algo dado como idealizaram Martha Feldman e Wanda Orlikowski, além de outros, valorizando a organização como um acontecimento, ou seja, como um conjunto de fenômenos processuais, habituais e emergentes, contribuindo, desse modo, para a desnaturalização da gestão.

\section{Organizações do Dia-a-Dia: Práticas e Perspectivas}

Só recentemente a ciência (ou a arte) administrativa tem compreendido a mudança e a instabilidade como rotineiramente presentes na realidade social, superando a noção de que a transformação e a improvisação são casos especiais da ordem e da estabilidade (um epifenômeno) e fazendo-nos crer que, mesmo as rotinas, são potencialmente instáveis, fruto de realizações emergentes 
(Tsoukas \& Chia, 2002). Esse deslocamento de perspectiva nos faz prestar atenção em como os processos de mudança precipitam em resposta a eventos internos/externos à organização e em quais forças orientam tal mutação.

Entendemos que uma das barreiras para tal deslocamento está no modo em que a Administração enxerga as organizações. Neste ensaio, buscamos, pois, superar tal limitação apoiando-se em teóricos vinculados à teoria da prática, os quais apreendem as organizações menos por sua dimensão estrutural/estática e mais pelos aspectos relacional e transformacional manifestados no fluxo de realizações ordinárias, que configuram práticas discursivas e não-discursivas, não negando - na verdade, perseguimos essa faísca, essa fratura - o caráter dialético entre as estruturas sociais imanentes nas práticas e a agência individual, como em Fairclough (2005) e Schatzki (2006). Compartilham desse ponto de vista diferentes autores que escreveram sobre as organizações como processos (processoriented), tais como Karl Weick, Martha Feldman e Wanda Orlikowski, ou como pós-processuais (usando expressão de Chia \& Mackay, 2007). Os últimos diferenciam-se dos primeiros, na medida em que acreditam na mudança/improvisação não como uma propriedade da organização, mas na organização como uma propriedade da mudança, isto é, na mudança como uma condição de possibilidade da organização (Tsoukas \& Chia, 2002).

De fato, podemos enxergar as organizações como um padrão - como fazemos, quando utilizamos as lentes da teoria da prática (ver Gherardi, 2015; Miettinen et al., 2010; Reckwitz, 2002; Schatzki, 2005), mas tal padrão emerge da própria mudança, criando uma realidade estável-instável. Enxergar a organização dessa forma significa compreendê-la: (a) como socialmente definida por um conjunto de regras que objetiva estabilizar uma realidade em constante mudança, tornando o comportamento humano mais previsível, e (b) como um resultado (um padrão ou um conjunto deles) emergente da aplicação reflexiva de regras em um contexto local, ao longo do tempo (Cooper, 1990; Tsoukas \& Chia, 2002).

Assim, organizar implica generalizar; é o processo de subsumir detalhes em categorias genéricas. No entanto, embora as categorias genéricas e os fins para os quais elas podem ser utilizadas são, em qualquer momento, dados aos membros da organização, elas são, no entanto, socialmente definidas. Além disso, essas categorias estão sujeitas a mudanças potenciais: a estabilidade de seus significados é mantida precariamente. A organização é tanto uma estrutura dada (ou seja, um conjunto de categorias cognitivas genéricas estabelecidas) e um padrão emergente (isto é, a adaptação constante dessas categorias às circunstâncias locais). As categorias cognitivas institucionalizadas são desenhadas por indivíduos em ação, mas, no processo, as generalizações estabelecidas podem ser complementadas, corroídas, modificadas ou, de qualquer forma, interpretadas em muitas formas imprevisíveis (Tsoukas \& Chia, 2002, p. 573, tradução nossa).

Czarniawska (2006) cita que a noção de organizing pressupõe um (re)começo diário; um processo contínuo, no qual a experiência do dia anterior é instrutiva, mas não determinante do que será feito a cada dia, ou seja, da organização que surge a cada dia. Não há uma essência sólida, que não se modifica. Há um processo de atribuição de sentido - sensemaking de Weick ou a inter-relação entre as categorias cognitivas genéricas e emergentes na citação acima - que conecta as ações passadas, as presentes e também os artefatos, formando uma malha estável-instável, que "representa a única estrutura que há" (Czarniawska, 2006, p. 1672).

O conceito de estrutura é aqui evocado no seu sentido frouxo, representando uma ordem precária (uma organização/modo de organizar a realidade), uma memória social inerente à prática (a estrutura reside nas práticas), portanto uma memória da prática (practice memory), como empregado em Schatzki $(2006)^{(1)}$. O autor propõe que enxerguemos as organizações como elas acontecem, o que significa apreendê-las como um conjunto de ações, que executadas geram performances, ou seja, práticas. No entanto, há algo que as dirige (sem que tal noção implique determinismo), para além do visível, i. e., das regras e orientações explícitas que interferem em sua execução. Aqui atua a noção de memória da prática, que confere uma integibilidade para a ação e forja uma identidade para os indivíduos e as coisas. Assim, memória da prática (ou memória coletiva/social) é a "persistência da estrutura do passado até o presente" (Schatzki, 2006, p. 1868); é a "persistência da estrutura de uma prática" (Schatzki, 2006, p. 
1869). Em Schatzki (2005), tal conceito é apresentado, de modo ainda embrionário, com o nome de mente social.

Essa perspectiva, embasada na noção de temporalidade existencial, incutida na obra Being and Time, de Martin Heidegger, contrapõe-se ao tempo objetivo (tempo do relógio), categoria definida pela noção de que "todos os eventos, ou posições temporais (momentos) ocorrem antes e depois de outros eventos ou posições" (Schatzki, 2006, p. 1865, tradução livre). Schatzki, no rastro de Heidegger, propõe que pensemos na estrutura/ordenação como o locus da experiência/vivência, onde passado, presente e futuro se fundem.

A dimensão futura da atividade, em direção a algo projetado, está agindo para um fim. A dimensão passada da atividade, partindo de algo dado, está respondendo a alguma coisa ou agindo à luz disso, ou seja, motivada. O presente da atividade é a própria atividade. O tempo de atividade está, portanto, atuando em direção a um fim que vem do que motiva. É um fenômeno teleológico (Schatzki, 2006, p. 1871, tradução nossa).

Compreender as organizações em tempo real significa observar as duas dimensões temporais ligadas às práticas: o tempo objetivo e o tempo da experiência. A trama da organização é a junção das ações no aqui e agora (emergência dos processos/eventos) com a lógica imanente (coocorrência do passado, presente e futuro) na prática, manifestada através do que estamos chamando de estrutura, ordenação ou memória organizacional. Naturalmente, nem todos na organização têm a mesma memória. Diferentes indivíduos têm acesso a diferentes passados, presentes e futuros, dependendo de seu status, experiência, habilidade, dentre outros.

Outra faceta da trama da organização são os arranjos sociomateriais (pessoas, artefatos, organismos e coisas) que dão subsídio às práticas e também são modificados por elas, portanto são também elementos constituintes dessas últimas.

Assim, uma organização é um nexo de práticas e arranjos materiais. As primeiras são formadas por uma multiplicidade de ações estruturadas no espaço-tempo. Tal estrutura, ou ordenação da prática, é composta por quatro elementos: (a) um conjunto de conhecimentos que permitem aos indivíduos realizar ações; (b) regras que podem ser obedecidas ou não; (c) uma orientação teleológica-afetiva, que diz respeito aos objetivos e emoções que se deseja alcançar com tais práticas; (d) o domínio de uma compreensão geral sobre a natureza das práticas que se deseja engajar (Schatzki, 2005, 2006).

Em suma, compreender uma organização como ela acontece, envolve

(1) [conhecer] a trama da organização em tempo real, os desdobramentos das atuações de suas ações; (2) [levar em consideração a] memória da organização, a persistência da estrutura organizacional do passado para o presente, juntamente com o complexo de ações, pensamentos, experiências, habilidades que assegura essa memória; (3) [reconhecer] o potencial envolvimento de artefatos materiais nas futuras tramas da organização; e (4) [conhecer] a infraestrutura causal que suporta as tramas e a memória da organização (Schatzki, 2006, p. 1870, tradução nossa).

Entendemos, a partir das análises anteriores, que a organização se torna um objeto de estabilidade vacilante, em função das ações e relações estabelecidas com outros humanos e objetos (a relação humanos e não-humanos é concebida de modos distintos nas várias abordagens vinculadas ao campo da teoria da prática. Essas distinções não são relevantes para o presente trabalho, embora o decolonialismo também esteja relacionado com a emergência de teorizações que reclamam uma simetria entre os dois pares dessa relação. A esse respeito, ver Gherardi, 2015). Para Tsoukas e Chia (2002), mudar é uma improvisação constante realizada pelos indivíduos numa tentativa de atribuir significado a suas experiências e agir coerentemente com o mundo. Assim, a improvisação é um esforço de acomodação a novas experiências, dito doutra forma, é a inventidade humana a serviço de um processo de ajustamento no mundo (de ser e estar no mundo). É claro que as organizações sofrem pressões internas e externas que as fazem alterar suas rotinas, no entanto, tais padrões de resposta são endogenamente condicionados. Portanto, o foco deve estar em explorar "o quê, como, onde, com quem e o porquê de 
aspectos particulares da autocompreensão de uma organização serem tornados relevantes em situações concretas ao longo do tempo" (Tsoukas \& Chia, 2002, p. 578, tradução nossa).

Para Fairclough (2005), Schatzki (2006) e Tsoukas e Chia (2002), a ênfase no estudo das organizações deve estar em capturar o dinamismo e a natureza mutante da vida organizacional: as organizações não devem ser tratadas como entidades, mas como um constante organizing. Manning (2008) sugere que a organização, como tradicionalmente é vista, refere-se ao que é observável por um observador externo, sendo o resultado de uma racionalização ex post facto, que termina por enxergá-la como uma rede de relações fixas.

O que propomos aqui é outro entendimento, como esperamos ter ficado claro. Em suma, argumentamos que a organização é um acontecimento vivo (que não cessa de ser construído), materializado pelos fatos, decisões e relações, que emerge quando a ação humana estabelece uma dialética com os padrões estabelecidos, presentes sob a forma de uma memória organizacional. Portanto, o organizing está sujeito às condições de possibilidade geradas pela estrutura e pela agência dos membros da organização (Fairclough, 2005).

Naturalmente, o que entendemos por mudança (por organizing) - influenciados por Tsoukas e Chia (2002), especialmente - não se limita (portanto, não exclui) às alterações que são institucionalizadas nas organizações. Se assim procedêssemos, perderíamos as nuanças (nível microscópico de análise) cotidianas, deixaríamos escapar o subterrâneo em que habita a organização. Deixaríamos escapar a improvisação cotidiana, i. e., toda a ação humana - que, no fundo, consiste no refazimento contínuo de crenças e hábitos - não incorporada ao sistema formal organizacional. $\mathrm{O}$ organizing não está em nenhum dos dois polos (hegemonia ou improviso). Ele está na tensão entre ambos - e a contribuição de Fairclough (2005) é muito importante para consolidar essa visão (ver, a esse respeito, sua argumentação na p. 929). Assim, estudar as organizações sob a lógica do organizing, significa identificar os padrões hegemônicos e as improvisações (mudanças microscópicas), examinar a relação e as condições que possibilitam o surgimento de ambas; e captar como os indivíduos (re)constroem suas percepções, crenças e hábitos em resposta a mudanças internas e externas às organizações.

Enxergar as organizações dessa forma significa colocar nossa atenção na experiência vivida diariamente e no papel das assimetrias de poder na consolidação e transformações dessas práticas cotidianas.

\section{Discussão}

Disso incorre que, ao trazer a teoria da prática como aporte teórico-metodológico propomos reconstruir (no processo de escrita científica) as organizações na medida em que captamos as séries de operações objetivas que as estabilizam e as tornam possíveis no mundo em que vivemos. Tal dinâmica recai sobre uma crítica ontológica da constituição da realidade organizacional.

Acreditamos que a realidade organizacional não possa ser interrompida em sua dinâmica. E, por isso, para nós, estudar as organizações é estudar o fluxo, as informações que são geradas no cotidiano, os saberes que se desenvolvem na vida gregária e que se recriam pela agência do ambiente, dos objetos e das próprias formas de organizar já associadas a uma organização. Capturar o momento da organização é impossível sem perceber a ligação entre as práticas organizacionais - projetar futuros, controlar o tempo e o espaço, adequar os corpos, organizar os elementos objetivos, lidar com a agência dos humanos e dos não-humanos. É nessa tensão entre uma prática e outra que localizamos a possibilidade de capturar o organizacional.

Nesse sentido, caminhar em direção a uma descrição dos modos de organizar (práticas organizativas) capturados localmente, isto é, de uma descrição de como essas organizações se manifestam, nos coloca o desafio de reconstruir o organizacional na medida em que nos defrontamos 
com tais fluxos de um cotidiano que, muitas vezes, passa ao largo dos moldes universalizados pela teoria hegemônica da modernidade ocidental.

Tais práticas organizativas podem ser identificadas em fontes além do convencional: (a) no registro antropológico de sociedades indígenas (Clastres, 2014), ou (b) no registro de obras que tratam de movimentos que se contrapuseram contra o poder hegemônico em sua época: revoltas como a Guerra dos Bárbaros (1682), como a Cabanagem (1833), entre outras comunidades alternativas como Canudos (Martins, 2001), entre outros registros históricos que nos dão indícios de memórias e práticas existentes no Brasil pré-moderno. As tradições existentes nestes lugares se constituem como rica fonte de dados para possíveis estudos.

Da mesma forma, a análise decolonial das organizações deve partir de perspectivas epistemológicas centradas no Outro e nas relações de proximidade entre os agentes. O que propomos é que sejam abandonados os pressupostos econômico-racionais que ditam as relações de proxemia para que se pense a formação de laços humanos que remontem a outras dimensões, como a confiança, o afeto, o compadrio, a cumplicidade, a alteridade, o cuidado, etc. O reconhecimento do Outro nas organizações e a mecanização das relações devem ser problematizadas para lançar um olhar mais profundo e crítico no cerne do que cria um elo de ligação entre os sujeitos em espaços alternativos.

Tais organizações podem ser comunidades que são geograficamente isoladas da modernidade ocidental ou por grupos que optam por se afastar dessas lógicas para constituir seus próprios hábitos, costumes, tradições, ou mesmo sistemas próprios de troca, como o escambo ou moedas alternativas.

Chamamos a atenção para o fato de que toda análise decolonial das práticas deve estar atenta a dois fatores: (a) aos aspectos históricos que constituem as práticas de organizações alternativas, como as tradições, as lendas, os mitos e as estórias que compõem o imaginário, as práticas cotidianas e os desejos futuros dos agentes (o que se busca com aquela forma organizativa), bem como (b) quais são os entraves históricos ou resultantes das hegemonias que se contrapõem à autodeterminação dos grupos, dificultando o seu seguimento e a sua expansão para outros lugares.

Entendemos, por fim, que o pesquisador deve se posicionar em defesa dessas sociedades alternativas, visto que não apenas será responsável apenas pela transmissão de seu entendimento sobre as práticas de organizações alternativas, mas também de seus conhecimentos, suas regras, suas relações teleológica-afetivas e sobre a natureza das práticas, mas também pela denúncia das práticas hegemônicas opressoras que exercem pressão pela normalização das organizações e sua respectiva colonização. Organizações Outras são espaços de resistência, em que os agentes constroem sua própria realidade a partir de pressupostos próprios - por essa razão, trazem a essência da diversidade. O resumo de tais ideias pode ser visualizado na Figura 1: 


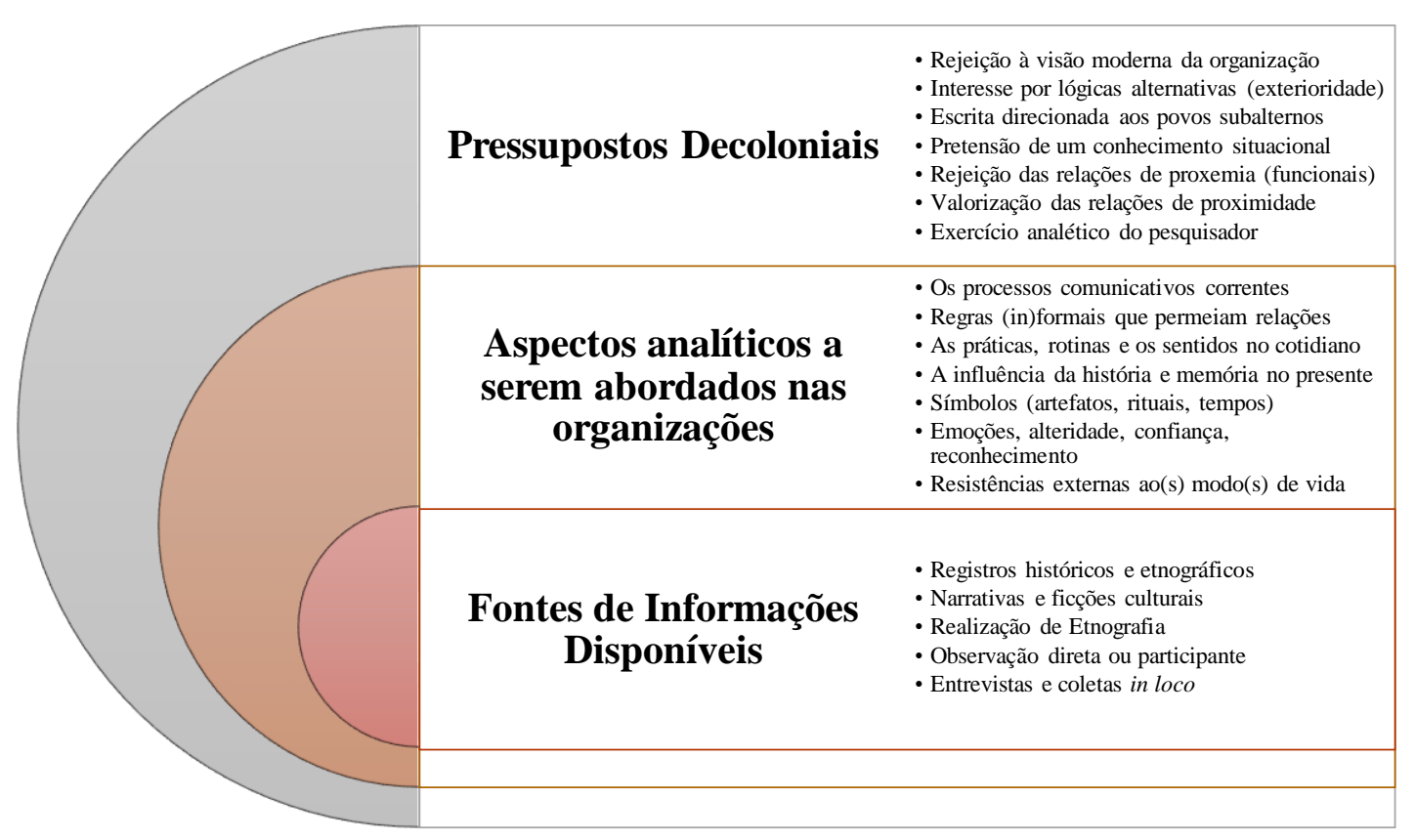

Figura 01. Representação Esquemática dos Construtos para a Pesquisa Fonte: Elaborado pelos autores.

Para capturar as organizações outras, portanto, acreditamos que a abordagem decolonial oferece um recorte necessário para os Estudos Organizacionais que podem e devem se debruçar sobre as organizações que são formadas dentro do país, estado, região e município em que vivemos. A generalização e a tendência a emparelhamento teórico com a totalidade do mainstream da Administração têm sufocado a experiência da pesquisa em organizações não hegemônicas e reduzido o âmbito organizacional ao padrão estadunidense/europeu de organização ideal.

Fica claro, para nós, que a analítica (ou atitude) decolonial proposta acima reclama aproximações com epistemologias de natureza processual, entendidas, no contexto deste ensaio, como abordagens vinculadas à (meta)teoria da prática. Na sequência, discorremos sobre um princípio basilar da teoria da prática, a saber: a construção social (cultural, histórica) da realidade. Consideramos que essa concepção guarda uma relação de proximidade com a analítica decolonial apresentada neste manuscrito.

Podemos dizer que as práticas são conjuntos organizados de ações, que se ligam a outros, formando uma constelação/arranjo muito amplo, que constitui o domínio básico de estudo das Ciências Sociais (Hui, Schatzki, \& Shove, 2017). Para a teoria da prática, esse domínio básico (ou seja, a realidade, o mundo) é socialmente construído: não existe uma realidade social objetivamente dada e única a todos (realidade a priori) e, sim, concepções coletivamente construídas, permanentemente. Essa afirmação é fundamental, pois representa o elo entre os movimentos virada da prática (Schatzki et al., 2001) e virada linguística (Alvesson \& Kärreman, 2000). Gherardi (2015) compreende que a teoria da prática incorpora os deslocamentos sugeridos pela virada linguística, resumidos, no contexto deste ensaio, na crítica ao paradigma da linguagem como sistema de representação do mundo, concepção que compreende a linguagem como um espelho fiel da realidade (Alvesson \& Kärreman, 2000).

A teoria da prática acolhe a noção de que (a) a linguagem é portadora/condutora de relações de poder por meio de sua capacidade de construir/anular significados (e, portanto, identidades) e fenômenos; (b) a linguagem é elaborada a partir de um contexto socialmente situado (demarcado pelo espaço-tempo e pela cultura); (c) existe uma relação entre o que se diz e as condições de produção dessa fala, ressaltando que há um sentido exterior na linguagem falada. Valoriza-se, portanto, a posição sóciohistórica dos enunciadores; (d) todo discurso possui uma ideologia subjacente. Em outros termos, questões relevantes para as Ciências Sociais como a possibilidade de ação e transformação social; o estabelecimento da hegemonia, do senso comum e dos movimentos de resistência; a construção identitária; as dinâmicas de poder; a legitimidade do saber; a formação das instituições, etc., podem ser 
compreendidas como tensões entre as práticas discursivas. Quem produz esses discursos, como eles adquirem concretude, a quais interesses eles servem? São perguntas que se tornam essenciais.

Portanto, as organizações podem ser lidas como um complexo de formações ideológicodiscursivas (FID), no qual se considera a hegemonia, ideologia e discurso (Fairclough, 2005). A partir dessa perspectiva, interessa ao pesquisador compreender os padrões de produção, reprodução e transformação das práticas organizativas: como os discursos emergem (a quais outros discursos ele se associa), se consolidam ou não; como são apropriados, transformados ou não; como saem de moda e depois retornam; como modificam os modos de agir tradicionais, como estabelecem prioridades, definem agendas, criam identidades, hierarquizam culturas, silenciam/acentuam determinadas vozes; etc. Cabe ao pesquisador empreender uma genealogia das práticas, isto é, descrever as associações de eventos que levam a consolidação de um determinado estado de coisas - fenômenos, instituições, redes de colaboração, etc. (Schatzki, 2014).

Uma organização é um fenômeno político (a resultante da relação entre sujeitos sociais, que manifestam distintos interesses e valores, disparando processos de negociação, conflito e dissenso) e vivo, isto é, as organizações são uma multiplicidade de processos (visão multinível) no aqui e agora, ligados a uma história - lógica que remente às noções de agenciamento (conexões ou em conexão com), de estados de alternância entre estabilidade-instabilidade e desconstrução/construção. No escopo da teoria da prática, as organizações são compreendidas menos por sua dimensão estrutural/estática (a partir de categorias tradicionais, tais como hierarquia, porte, eficiência/eficácia econômica, áreas funcionais, dentre outras) e mais pelo aspecto relacional manifestado no fluxo de ações cotidianas, que configuram práticas compostas por elementos discursivos e não-discursivos e humanos e não-humanos. Esse modo de compreender-conhecer (uma onto-epistemologia) as organizações é chamado por Gherardi (2015) de epistemologia relacional.

O entendimento das organizações como um fenômeno político e vivo enfatiza o caráter emergente e contingente das ações, a natureza mutável dos contextos e confere um papel importante a improvisação, negociação e a persuasão. Tal afirmativa demanda, em alguma medida, a recuperação de uma sensibilidade etnográfica, cartográfica ( $a$ lá Deleuze e Guattari) ou de abordagens afins preocupadas em seguir (rastrear) as práticas dos atores sociais e em compreender que o ato de conhecer se dá a partir da vivência no mundo (imersão no plano da vida, no vivido) e não se separa do fazer. Requer, ao mesmo tempo, que o pesquisador desconfie da proposta empiricista centrada num observador imparcial e conceba o processo de produção do saber sobre o Outro como fruto da interação subjetiva (influenciada por assimetrias de poder) entre o sujeito que conhece e o sujeito que se deseja conhecer.

Em outras palavras, é por meio de práticas epistêmicas que os pesquisadores (ou mais genericamente, aquele que deseja conhecer algo no mundo) constroem os objetos do conhecimento (a ontologia) e os métodos para produzir conhecimento (a epistemologia): os pesquisadores estão dentro/no interior das práticas que estudam, portanto o conhecimento está situado dentro das formas de vida e é o resultado de negociações sociais em que interesses, ideologias e contingências se manifestam (Gherardi, 2015).

Essa abordagem oferece um modo específico de compreender-conhecer as organizações, isto é, de responder às perguntas $O$ que vem a ser uma organização? e Como devemos estudá-las?. O que propomos no presente ensaio é que a resposta dada pela teoria da prática a ambas indagações, representa um caminho alinhado à analítica decolonial, que tem como um de seus princípios basilares o uso de epistemologias que valorizam o contexto histórico, a visão de mundo de organizações alternativas e suas lutas identitárias (as lutas contra o silenciamento do Outro e a favor do reconhecimento do Outro). Entendemos que o presente ensaio é um esforço pioneiro nesta direção, que se alinha às expectativas dos principais teóricos da prática ativos contemporaneamente. Tais pensadores insistem que o desenvolvimento contínuo desse campo de estudo virá da articulação de seus princípios com outros campos do saber (Hui, 2014). 


\section{Considerações Finais}

Entendemos que uma análise que se proponha a, de fato, pesquisar organizações precisa compreender as várias dimensões, a dinâmica e a rede de fatos em que se inserem os fenômenos que criam, processam e reconstroem tais organizações. A compreensão da dinâmica processual de estabilização das organizações abre caminhos para pensarmos em possibilidades de organizações que não encontram registro do modo tradicional de se fazer ciência em Administração.

A abordagem decolonial de Dussel pode abrir caminhos para pensarmos numa aproximação com organizações alternativas (ou não hegemônicas) e, portanto, numa dinâmica da construção local de práticas organizativas; isto é, outras formas de organizar, construir ou recriar o cotidiano organizacional no refazimento diário das formas de agir e pensar que não esteja vinculado a lógica dos modelos oferecidos tradicionalmente pela teoria veiculada no campo da Administração.

A teoria da prática, por outro lado, na forma como a entendemos, oferece um caminho teóricometodologico para a estabilização dos fatos que constroem, ou dito doutra forma, realizam a organização. Capturar o dinamismo, a mudança e a teia de relações que são construídas durante o processo organizacional nos leva à possibilidade de não apenas desconstruir, mas de reagregar organizações e incluir ontologicamente outros modos de existência organizacionais no registro e na história dessa ciência.

Quando sugerimos o termo organizações outras é claramente uma referência a outras formas de organizar, planejar, controlar, coordenar, resistir, ressignificar - isto é, a outras práticas organizativas. Não só porque as organizações se manifestam de maneiras muito distintas nas expressões culturais locais, mas porque a visão que se tem de tais práticas é bastante limitada quando são associadas às organizações formais. Todo o contexto e a ligação de tais práticas a um fluxo de movimentos operativos que independem da ação humana é desconsiderado, além de ser também desconsiderada a inter-relação entre a dinâmica das forças criativas humanas e o imperativo do momento organizacional. Para capturarmos tais formas, acreditamos que seja necessário mudar radicalmente nossa visão sobre o que são as organizações e como elas se manifestam.

O alinhamento político-epistêmico que estamos sugerindo parte da concepção que as organizações não podem ser generalizadas e não podem assumir modelos totais - ainda que eles existam num plano teórico dedicado a normatização da vida organizacional. Deve haver, portanto, um senso profundo de que a investigação de o que são as organizações não está completa.

Temos observado o surgimento de diversas formas organizacionais que não encontram lugar no modelo reificado de organização, como o caso de ecovilas, de organizações auto-geridas e moldes não tradicionais de organizações que têm suas práticas teoricamente comprometidas, quando são obrigadas a se alinharem à perspectiva do mainstream em Administração. Comumente, se veem as práticas cotidianas dessas organizações sendo caracterizadas como disfunções, incapacidade de lidar com conflitos, improdutividade, dentre outros aspectos que partem da noção de que organizações são entidades para realizações imediatas de eficiência e eficácia. Esse tipo de associação inviabiliza a compreensão dos fluxos de informações que são gerados pelos conflitos, pela experimentação e, especialmente, pela dinâmica mutante da cocriação da realidade imediata.

\section{Nota}

${ }^{1}$ A leitura de Fairclough (2005) ajuda a compreender o conceito de memória da prática de Schatzki. 


\section{Referências}

Abdalla, M. M., \& Faria, A. (2017). Em defesa da opção decolonial em administração/gestão. Cadernos EBAPE.BR, 15(4), 914-929. http://doi.org/10.1590/1679-395155249

Alcadipani, R. (2011). Academia e a fábrica de sardinhas. Organizações \& Sociedade, 18(57), 345-348.

Alcadipani, R., \& Caldas, M. P. (2012). Americanizing Brazilian management. Critical Perspectives on International Business, 8(1), 37-55. https://doi.org/10.1108/17422041211197

Alcadipani, R., Khan, F. R., Gantman, E., \& Nkomo, S. (2012). Southern voices in management and $\begin{array}{llll}\text { organization } & \text { knowledge. } & \text { Organization, } & 19(2),\end{array}$ https://doi.org/10.1177/1350508411431910

Alvesson, M., Deetz, S. (1996). Critical theory and postmodernism approaches to organizational studies. In S. Clegg, C. Hardy, \& W. Nord (Eds. ), Handbook of organization studies (pp. 255-346). London: Sage. https://doi.org/10.4135/9781848608030.n8

Alvesson, M., Hardy, C., \& Harley, B. (2008), Reflecting on reflexivity: Reflexive textual practices in organization and management theory. Journal of Management Studies, 45(3), 480-501. https://doi.org/10.1111/j.1467-6486.2007.00765.x

Alvesson, M., \& Kärremann, D. (2000). Taking the linguistic turn in organizational research: Challenges, responses, consequences. The Journal of Applied Behavioral Science, 36(2), 136158. https://doi.org/10.1177/0021886300362002

Ballestrin, L. (2013). América Latina e o giro decolonial. Revista Brasileira de Ciência Política, (11), 89-117. http://doi.org/10.1590/S0103-33522013000200004

Barros, A. N. (2014). Uma narrativa sobre os cursos superiores em Administração da FACE/UFMG: Dos primeiros anos à sua unificação em 1968. Cadernos EBAPE.BR, 12(1), 7-25. Recuperado em 14 de novembro, 2017, de http://bibliotecadigital.fgv.br/ojs/index.php/cadernosebape/article/view/9178/17307. http://doi.org/10.1590/S1679-39512014000100003

Barros, A. N., \& Carrieri, A. d. (2013). Ensino superior em Administração entre os anos 1940 e1950: Uma discussão a partir dos acordos de cooperação Brasil-Estados Unidos. Cadernos EBAPE.BR, $11(2), 256-273$.

Barros, A. N., \& Carrieri, A. de P. (2015). O cotidiano e a história: Construindo novos olhares na administração. Revista de Administração de Empresas, 55(2), 151-161. http://doi.org/10.1590/S0034-759020150205

Barros, A. N., Cruz, R. C., Xavier, W. S., \& Carrieri, A. de P. (2011). Apropriação dos Saberes Administrativos: Um olhar alternativo sobre o desenvolvimento da área. Revista de Administração Mackenzie, 12(5), 43-67.

Bertero, C. O., Alcadipani, R., Cabral, S., Faria, A., \& Rossoni, L. (2013). Os desafios da produção de conhecimento em administração no Brasil. Cadernos EBAPE.BR, 11(1), 182-196.

Bourdieu, P. (1989). O poder simbólico (F. Tomaz, Trad.). Rio de Janeiro: Bertrand Brasil.

Carrieri, A. de P. (2012). A gestão ordinária (Tese para concurso de professor titular). Universidade Federal de Minas Gerais, Belo Horizonte, MG, Brasil. 
Carvalho, V., Filho, Ipiranga, A. S., \& Faria, A. (2017). (De)Colonialidade na educação em administração: Explorando limites e possibilidades. Arquivos Analíticos de Políticas Educativas, 25(47), 1-34. http://doi.org/10.14507/epaa.25.2676

Cavalcanti, M. F., \& Alcadipani, R. (2013). Organizações como processos e teoria ator-rede: A contribuição de John Law para os estudos organizacionais. Cadernos EBAPE.BR, 11(4), 556-568.

Chakrabarty, D. (2011). The politics and possibility of historical knowledge: Continuing the $\begin{array}{llll}\text { conversation. Postcolonial 243-250. } & \text { Studies, }\end{array}$ http://doi.org/10.1080/13688790.2011.585959

Chia, R., \& Mackay, B. (2007). Post-processual challenges for the emerging strategy-as-practice perspective: Discovering strategy in the logic of practice. Human Relations, 60(1), 217-242. https://doi.org/10.1177/0018726707075291

Clastres, P. (2014). A sociedade contra o Estado. São Paulo: Editora Cosac Naify.

Collinson, D. L. (2006). Rethinking followership: A post-structuralist analysis of follower identities. The Leadership Quarterly, 17(2), 172-189. https://doi.org/10.1016/j.leaqua.2005.12.005

Cooper, R. (1990). Organization/disorganization. In J. Hassard \& D. Pym (Eds.), The theory and philosophy of organizations: Critical issues and new perspectives (pp. 167-197). Abington, MA: Routledge.

Couto, F. F., \& Carrieri, A. de P. (2018). Enrique Dussel e a filosofia da libertação nos estudos organizacionais. Cadernos EBAPE.BR, 16(4), 631-641. https://doi.org/10.1590/1679-395169213.

Czarniawska, B. (2006). A golden braid: Allport, Goffman, Weick. Organization Studies, 27(11), 16611674. https://doi.org/10.1177/0170840606068344

Davel, E., \& Alcadipani, R. (2003). Estudos críticos em administração: Aprodução científica brasileira nos anos 1990. Revista de Administração de Empresas, 43(4), 72-85. http://doi.org/10.1590/S0034-75902003000400006

Dussel, E. D. (1977). Filosofia da libertação na América Latina. Piracicaba, SP: Unimep.

Dussel, E. D. (2005). Filosofia da libertação: Crítica à ideologia da exclusão. São Paulo: Paulus.

Escobar, A. (1988). Power and visibility: Development and the invention and management of the third world. Cultural Anthropology, 3(4), 428-443. https://doi.org/10.1525/can.1988.3.4.02a00060

Fairclough, N. (2005). Peripheral vision - discourse analysis in organization studies: The case for critical realism. Organization Studies, 26(6), 915-939. https://doi.org/10.1177/0170840605054610

Frenkel, M., \& Shenhav, Y. (2006). From binarism back to hybridity: A postcolonial reading of management and organization studies. Organization Studies, 27(6), 855-876. https://doi.org/10.1177/0170840606064086

Gherardi, S. (2015). To start practice theorizing anew: The contribution of the concepts of agencement and formativeness. Organization, 23(5), 680-698. https://doi.org/10.1177/1350508415605174

Heracleous, L. (2006). A tale of three discourses: The dominant, the strategic and the marginalized. Journal of Management Studies, 43(5), 1059-1087. https://doi.org/10.1111/j.14676486.2006.00629.x

Hui, A. (2014). [‡] Manifesto. [Working Paper n 4]. DEMAND Centre, Flórida, EUA. 
Hui, A., Schatzki, T., \& Shove, E. (2017). Introduction. In A. Hui, T. Schatzki, \& E. Shove (Eds.), The nexus of practices: Connections, constellations, practitioners (pp. 1-6). New York: Routledge.

Ibarra-Colado, E. (2006). Organization studies and epistemic coloniality in Latin America: Thinking otherness from the margins. Organization, 13(4), 463-488. https://doi.org/10.1177/1350508406065851

Ibarra-Colado, E. (2012). Cómo compreender y transformar los estudios organizacionales desde América Latina y no morir en el intento. In A. M. Martínez, R. de C. Rabiela, H. Vessuri, \& A. V. Corona (Coords.), Apropiación social del conocimiento y aprendizaje: Una mirada crítica desde diferentes ámbitos (pp. 17-38). Madrid: Plaza y Valdés Editores.

Manning, P. K. (2008). Goffman on organizations. Organization Studies, 29(5), 677-699. https://doi.org/10.1177/0170840608088767

Martins, P. E. (2001). A reinvenção do sertão: A estratégia organizacional de Canudos. Rio de Janeiro: Editora FGV.

Miettinen, R., Samra-Fredericks, D., \& Yanow, D. (2010). Re-turn to practice: An introductory essay. Organization Studies, 30(12), 1309-1327. https://doi.org/10.1177/0170840609349860

Misoczky, M. C., \& Camara, G. D. (2015). Enrique Dussel: Contribuições para a crítica ética e radical nos estudos organizacionais. Cadernos EBAPE.BR, 13(2), 286-314. http://doi.org/10.1590/1679395115875

Prasad, A. (2016). Toward decolonizing modern western structures of knowledge. In A. Prasad, P. Prasad, A. J. Mills, \& J. H. Mills (Eds.), The Routledge companion to critical management studies (pp. 161-199). London: Routledge.

Reckwitz, A. (2002). Toward a theory of social practices: A development in culturalist theorizing. European Journal of Social Theory, 5(2), 243-263. https://doi.org/10.1177/13684310222225432

Reed, M. I. (2010). Teorização organizacional: Um campo historicamente contestado. In S. R. Clegg, C. Hardy, \& W. R. Nord (Orgs.), Handbook de estudos organizacionais (Vol. 1, pp. 61-97). São Paulo: Atlas.

Rodrigues, S. B., Duarte, R. G., \& Carrieri, A. P. de (2012). Indigenous or imported knowledge in Brazilian management studies: A quest for legitimacy? Management and Organization Review, 8(1), 211-232. https://doi.org/10.1111/j.1740-8784.2011.00276.x

Schatzki, T. R. (2005). Peripheral vision: The sites of organizations. Organization Studies, 26(3), 465484. https://doi.org/10.1177/0170840605050876

Schatzki, T. R. (2006). On organizations as they happen. Organization Studies, 27(12), 1863-1873. https://doi.org/10.1177/0170840606071942

Schatzki, T. R. (2014). Larger scales [Working Paper nº 5]. DEMAND Centre, Flórida, EUA.

Schatzki, T. R., Cetina, K. K., \& Savigny, E. von (2001). The practice turn in contemporary theory. London: Routledge.

Tsoukas, H., \& Chia, R. (2002). On organizational becoming: Rethinking organizational change. Organization Science, 13(5), 567-582. https://doi.org/10.1287/orsc.13.5.567.7810

Weick, K. E. (1979). The social psychology of organizing. Reading-MA: Addison-Wesley.

Willmott, H. (1997). Management and organization studies as science? Organization, 4(3), 309-344. https://doi.org/10.1177/135050849743002 
Zilio, L. B., Barcellos, R. de, Dellagnelo, E. H., \& Assmann, S. J. (2012). Organizações contrahegemônicas ea possibilidade de redescoberta da política na modernidade: Uma contribuição a partir do pensamento de Hannah Arendt. Cadernos EBAPE.BR, 10(4), 789-80 https://doi.org/10.1590/S1679-39512012000400002

\section{Autores}

Felipe Fróes Couto

Avenida Presidente Antônio Carlos, 6627, Sala 4012, 31270-901, Belo Horizonte, MG, Brasil

E-mail: felipe.froes@outlook.com

Bruno Eduardo Freitas Honorato

Avenida Presidente Antônio Carlos, 6627, Sala 4012, 31270-901, Belo Horizonte, MG, Brasil

E-mail: brunoefh@gmail.com

Everton Rodrigues da Silva

Avenida Celina Ferreira Ottoni, 4000, 37048-395, Varginha, MG, Brasil

E-mail: everton.rsilva@gmail.com

\section{Contribuições}

$1^{\circ}$ autor: os aspectos centrais da reflexão sobre o decolonialismo são provenientes de sua pesquisa de doutoramento no CEPEAD/UFMG. Atuou na formatação e normatização do trabalho, bem como na elaboração da Discussão e Considerações Finais. É importante pontuar que esses dois tópicos do artigo foram construídos coletivamente pelos autores.

$2^{\mathrm{o}}$ autor: atuou na complementação das duas vertentes teóricas que sustentam o trabalho (decolonialismo e teoria da prática) e na articulação de ambas, a fim de que o artigo ganhasse coerência. Atuou na elaboração da Discussão e Considerações Finais.

$3^{\text {o }}$ autor: os aspectos centrais da reflexão sobre a teoria da prática são um resultado do seu processo de doutoramento no CEPEAD/UFMG. Atuou na elaboração da Discussão e Considerações Finais.

\section{Financiamento}

Os autores informaram que não há existência de apoio financeiro para a pesquisa neste artigo.

\section{Conflito de Interesses}

Os autores informaram que não há conflito de interesses.

\section{Verificação de Plágio}

A RAC mantém a prática de submeter todos os documentos aprovados para publicação à verificação de plágio, mediante o emprego de ferramentas específicas, e.g.: iThenticate. 